\title{
Changes in serum and cell homeostasis under irradiation: Factors of distant action
}

\author{
Irina Alchinova \\ Institute of General Pathology and Pathophysiology, Moscow, Russia
}

\section{Email address:}

alchinovairina@yandex.ru

\section{To cite this article:}

Irina Alchinova. Changes in Serum and Cell Homeostasis under Irradiation: Factors of Distant Action. American Journal of Life Sciences. Special Issue: Space Flight Factors: From Cell to Body. Vol. 3, No. 1-2, 2015, pp. 1-4. doi: 10.11648/j.ajls.s.2015030102.11

\begin{abstract}
Extracellular DNA-containing substances can be used as a marker of the balance between two processes: elimination of cells with critical number of lesions and repair of genetic material due to the work of adaptive systems. The idea of using this criterion was inspired by the results of measuring exDNA in blood plasma of chronically irradiated individuals. Here we used material obtained after gamma-irradiation (total dose 0.5 Gy) and subsequent culturing of PHA-stimulated human peripheral blood lymphocytes. The culture medium and exDNA isolated by various methods were treated with DNase and pronase. The concentration of free exDNA isolated by phenol extraction was an individual sign. The culture medium supernatant contained considerable amounts of exDNA in the form of nucleoprotein; cleavage of the protein component of this nucleoprotein considerably increased the size of fragments (from 1 to $20 \mathrm{~kb}$ ) and reduced their resistance to DNase.
\end{abstract}

Keywords: Extracellular DNA, Laser Correlation Spectroscopy, Radiation

\section{Introduction}

Genomic DNA and histone proteins packed in chromatin are known to constitute the major part of the cell nucleus. This compact packing, however, should provide accessibility of the DNA molecule for replication, transcription, and repair enzymes and for regulatory factors. Nucleosome is the smallest moiety of this compact chromatin packing. Previous studies have demonstrated accumulation of extracellular DNA (exDNA) enriched with CpG repeats in the blood of humans exposed radiation. ExDNA realizes its effects via TLR9 receptors and induces cascade reactions that stimulate the immune system and trigger enhanced cytokine production [1]. This "alarm signal" forces the cells to function in an emergency mode, which can lead to exhaustion of the organism reserves [2]. Along with this, exposure to low doses of $\gamma$-radiation is associated with secretion of proteins possessing both protective and cytotoxic properties [3].

The aim of this study was to characterize substances released from human lymphocytes after $\gamma$-irradiation.

\section{Materials and Methods}

In this work, we used culture media obtained after culturing of PHA-stimulated human peripheral blood lymphocytes. The blood was collected in sterile tubes with heparin. The following reagents were used for cell culturing: cytotoxicity- and mycoplasma-tested sterile fetal calf serum (Perbio-HyClone, USA; $1.6 \mathrm{ml}$ per flask), RPMI-1640 medium with $25 \mathrm{mM}$ HEPES and sodium bicarbonate $(6.2$ $\mathrm{ml}$ per flask), and PHA (phytohemagglutinin-P from Phaseolus vulgarios, Sigma, USA; $0.15 \mathrm{ml}$ per flask). The medium was also supplemented with glutamine and antibiotics $(5000 \mathrm{U} / \mathrm{ml}$ penicillin and $5000 \mu \mathrm{g} / \mathrm{ml}$ streptomycin). The cells were cultured in glass flasks $(1 \mathrm{ml}$ whole heparinized blood per flask). Irradiation was carried out on a $\gamma$-unit (Obninsk) with a beam power of $25 \mathrm{rad} / \mathrm{min}$ $(0.25 \mathrm{~Gy} / \mathrm{min})$ at a distance of $65 \mathrm{~cm}$ to a cumulative dose of $0.5 \mathrm{~Gy}$.

Culturing was carried out at $37^{\circ} \mathrm{C}$ for $52 \mathrm{~h}$. After incubation, the cells were removed by centrifugation. The culture medium was collected $(1.5 \mathrm{ml})$ into Eppendorf tubes and frozen for transportation.

ExDNA was isolated from the culture medium by two methods: routine phenol method and by method [4] using commercial kits manufactured by Omnix company. The method implies DNA adsorption from the solution on the filter.

The concentration of exDNA isolated by phenol method was measured fluorometrically on an LS 55 fluorescent spectrometer (PerkinElmer; UK) using a DNA-binding dye Hoechst $33258\left(\lambda_{\mathrm{ex}}=350 \mathrm{~nm}, \lambda_{\mathrm{fl}}=450 \mathrm{~nm}\right)$; fluorescence was measured over $1 \mathrm{~min}$. Fluorescence of the sample taken after complete hydrolysis of extracellular DNA with DNase 1 was used as the background fluorescence. 
For the identification and separation of DNA fragments isolated by various methods, electrophoresis in $1 \%$ agarose gel was performed. During separation in gel, the position of DNA was determined, because DNA bands in the gel were stained with a fluorescent DNA intercalating dye ethidium bromide (final concentration $0.5 \mu \mathrm{g} / \mathrm{ml}$ ). Fermentas kits were used as molecular weight markers. The presence of protein in samples was controlled by staining with Coumassi blue R250.

Subfraction composition of the obtained culture medium was analyzed by laser correlation spectroscopy (LCS) [5]. The method allows evaluating the ratio of particles of various sizes in biological fluids (serum, urine, etc.). The measurements and calculations yield a histogram of particle contribution (\%) into light scatter (ordinate) as a function of particle size (nm, abscissa).

Supernatants collected after cell irradiation contain a mixture of proteins, deoxyribonucleoproteins (DNP), RNA, etc. For calculation of the percent contribution of these particles, the samples were treated with DNase from bovine pancreas (Sigma, USA; specific activity $410 \mathrm{KU}$ ) and pronase from Strep. griseus (Calbiochem-Behring Corp., USA; specific activity 77,000 PUK). We compared LC histograms of the initial supernatant and samples treated with DNase and pronase.

DNase was dissolved in $0.15 \mathrm{M} \mathrm{NaCl}$ to a concentration of $80 \mathrm{KU} / \mathrm{ml}$. Culture medium $(50 \mu \mathrm{l})$ was mixed with $50 \mu \mathrm{l} 1$ $\mathrm{M}$ acetate buffer ( $\mathrm{pH} 5.0), 20 \mu \mathrm{l} 0.1 \mathrm{M}$ magnesium sulfate, and $200 \mu \mathrm{l}$ DNase solution. The samples were incubated for $10 \mathrm{~min}$ at room temperature.

The reaction with pronase was carried out in $0.01 \mathrm{M}$ Trisbuffer ( $\mathrm{pH} 7.8$ ) containing $0.01 \mathrm{M}$ EDTA and $0.5 \%$ sodium dodecyl sulfate. The enzyme solution in a buffer (concentration $40 \mathrm{mg} / \mathrm{ml}$ ) was incubated for $2 \mathrm{~h}$ at $37^{\circ} \mathrm{C}$ for removal of DNase and RNase activities; then, $50 \mu$ pronase solution was added to $50 \mu \mathrm{l}$ culture medium. The reaction mixture was incubated at $37^{\circ} \mathrm{C}$ for $2 \mathrm{~h}$.

\section{Results and Discussion}

In blood cells placed in the medium, two parallel processes take place: natural cell death during culturing (mediated by various mechanism of cell death) and realization of the compensatory mechanism aimed at repair of damages in the genetic material. Extracellular DNAcontaining substances released from the cells due to their radiation-induced death or damage can be used as the measure of the balance between these two processes: elimination of cells with critical number of lesions and repair of genetic material due realized by the adaptive systems. The idea of using exDNA content as the criterion was inspired by the results of measurements of this parameter in the blood plasma of chronically irradiated individuals [6]. In workers of nuclear-fuel factory, the contribution of small particles (6$8 \mathrm{~nm}$ ) into light scatter increased, while the contribution of large components $(300-400 \mathrm{~nm})$ decreased with increasing the irradiation dose. A significant correlation was revealed between the cumulative dose, dose over the last 9 months, and changes in the contribution of the specified particles into light scatter [7].

The content of exDNA isolated by standard phenol method in the control and irradiated samples greatly varied in different donors, which probably reflects the differences in the individual responses. The total concentration of exDNA is influenced by both cell death leading to the release of DNA fragments and activity of enzymes responsible for elimination of cell degradation products.

The size of exDNA fragments was measured by electrophoresis in $1 \%$ agarose gel. In a series of 18 samples, most fragments have a length of $20 \mathrm{k} . \mathrm{b}$.

The positive results obtained in isolating exDNA by the phenol method allowed us to use Omnix columns for exDNA isolation, which appeared to be a simpler way.

Comparison of LC histograms of the initial culture medium samples and DNA isolated from them showed evident shift towards larger particles in samples of isolated DNA. Removal of small particles from the initial samples on columns increases the contribution of large particles into light scatter (Fig. 1).

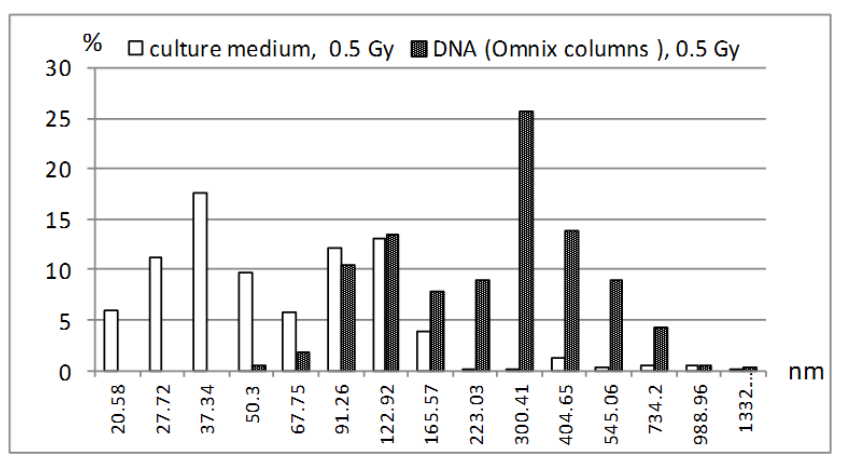

Figure 1. Comparison LC - histograms culture medium after exposure of lymphocytes in a dose of 0.5 Gy LC-histograms of the DNA extracted therefrom to the column at 0.5 Gy irradiation. The abscissa - the particle size in nanometers, vertical axis - percent contribution to light scattering.

Despite clear-cut differences in LC-histograms shown in Fig. 1, a coinciding area corresponding to $67.75-165.57 \mathrm{~nm}$ was seen; this probably represents DNA-proteins complexes.

The substance in samples is mainly presented by packed nucleoprotein fragments with a size of 1000-1500 b.p., which was confirmed by electrophoresis. Differences in the size of fragments isolated by phenol method and on columns is worthy of note. Removal of histone and nonhistone proteins responsible for DNA packing during phenol treatment increases the size of DNP fragments.

For verification of the DNP nature of exDNA, DNP fragments in further studies were treated with DNase and pronase destroying different components of the DNP complex.

Addition of the enzymes to initial culture media induced similar changes in the control and irradiated samples. After DNase cleavage of DNA fragments, particles with a size of 123-166 nm were still seen on LC-histograms, while 67-91 and 223-405-nm particles disappeared (Fig. 2A). 

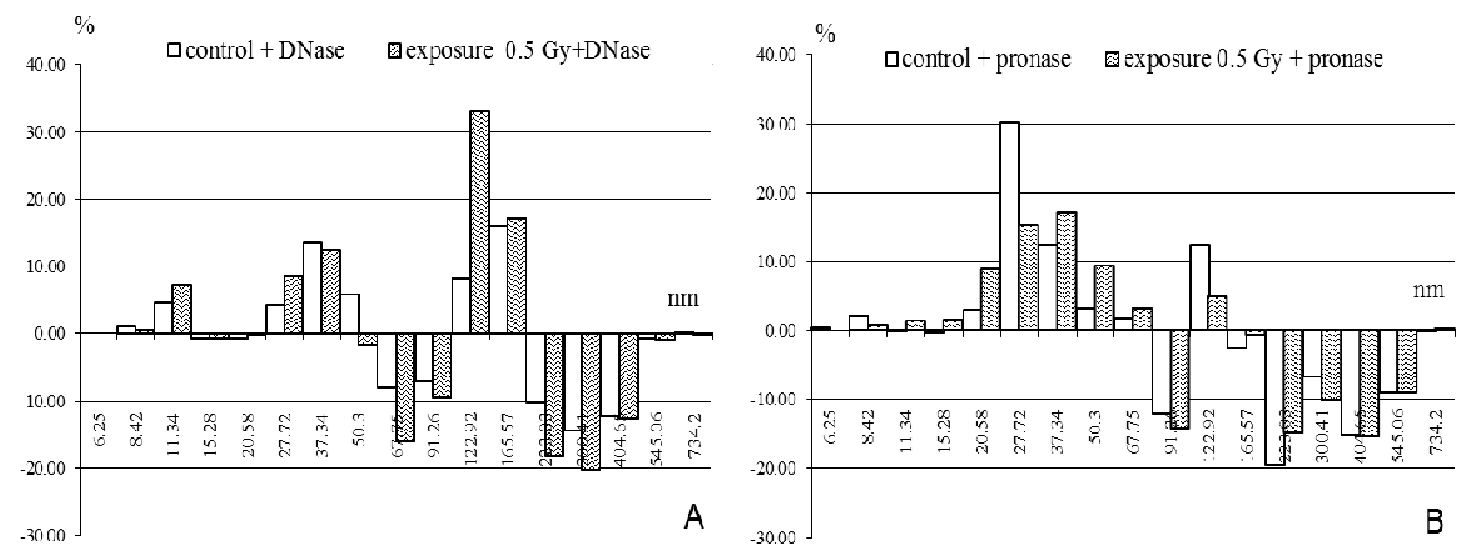

Figure 2. Difference of LC-histograms of initial control and irradiated samples after treatment with DNase (A) and pronase (B). Axes as in Figure 1.

Similar results were observed after addition of pronase cleaving proteins, except particles with the size of 123-166 $\mathrm{nm}$ were practically absent, while the contribution of small particles $(20-50 \mathrm{~nm})$ considerably increased (Fig. 1B).

The culture media includes various components and the difference between the LC-histograms of control and irradiated samples after enzyme treatment can be explained by the presence of components resistant to the used enzymes, e.g. lipids. Therefore, similar experiment was performed

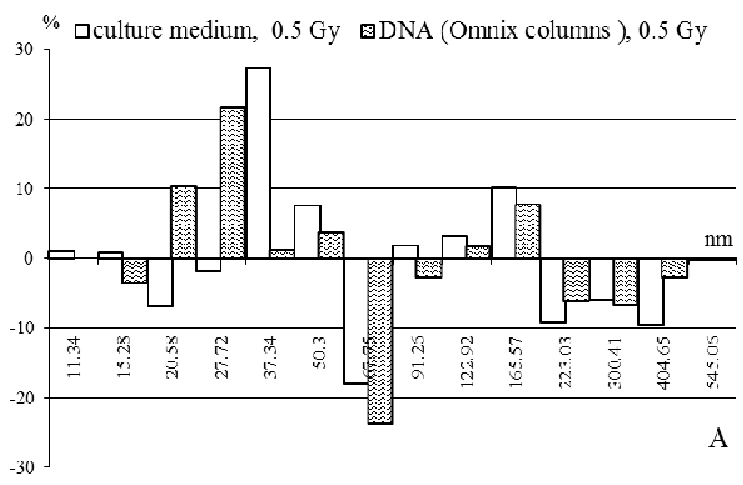

with DNA isolated on columns.

DNase treatment increased the contribution of small particles with a radius of $27.7-50 \mathrm{~nm}$. In the zone presumably corresponding to isolated DNA $(67.8-545 \mathrm{~nm})$, DNase treatment induced the following changes: 67.8-91.3 and 300$500-\mathrm{nm}$ particles were practically destroyed, and the zone of 122.3-166 nm was preserved, which suggests that DNA fragments isolated on columns are degraded by DNase in different ways (Fig. 3A).

30 \% - c culture medium, 0.5 Gy gDNA (Omnix columns ), 0.5 Gy

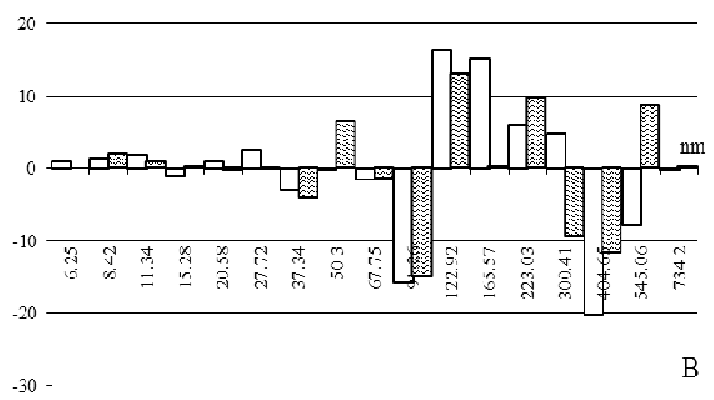

Figure 3. Differences of LC-histograms of DNA isolated on columns after treatment with DNase (A) and pronase (B) and LC-histogram of the enzyme used from the treatment. Axes as in Figure 1.

Pronase treatment also modified LC-histograms of DNA isolated on columns. These changes are similar to changes caused by DNase; in addition, the contribution of 123-166$\mathrm{nm}$ particles somewhat increased (Fig. 3B).

These findings suggest that fragments present in the culture medium are nucleoproteins consisting of components characterized by different resistance to enzyme treatment. The protein components of the complex play a protective role and limits accessibility of certain DNA sites.

Our experiments with isolation of free exDNA by the phenol method suggest that its concentrations are an individual sign. The culture medium obtained after culturing of PHA-stimulated human peripheral blood lymphocytes contains significant amounts of free DNA in the form of a nucleoprotein. Cleavage of the protein component of this nucleoprotein considerably increases the fragment size and reduces their resistance to DNase. Increased content of exDNA fragments in humans in the absence of the radioadaptive response agrees with the data on increased concentrations of $\gamma$-interferon in these individuals and attests to the immunostimualting function of exDNA.

The individual differences in the frequency of chromosomal aberrations persisting for a long time are well known phenomenon [8; 8]. Similar differences were recently observed in the reaction of non-irradiated cells to their placement into the culture medium from irradiated lymphocytes [10]. In view of the involvement of exDNA in the realization of the bystander effect [11], the characteristics and evaluation of individual peculiarities of secreted substances seem to be very promising for the formation of the criteria of radiosensitivity.

\section{References}

[1] NN Veǐko, AV Ermakov, NA Egolina, NA Liapunova, DM Spitkovskiū, "Activation of total and ribosomal RNA transcription under adapting doses of ionizing radiation inducing displacement of chromosome loci in human G0lymphocyte," Radiats Biol Radioecol., vol. 44, No 5, 2004, pp.501-508. 
[2] AV Ermakov, MS Konkova, SV Kostyuk, VL Izevskaya, AV Baranova, NN Veiko, "Oxidized extracellular DNA as a stress signal in human cells," Oxid Med Cell Longev. 2013;2013:649747. doi: 10.1155/2013/649747

[3] Klokov D., Criswell T., Leskov K.S., Araki S., Mayo L., Boothman D.A, "IR-inducible clusterin gene expression: a protein with potential roles in ionizing radiation-induced adaptive responses, genomic instability, and bystander effects," Mutat. Res., vol. 568, No. 1, 2004, pp.97-110

[4] Vogelstein B. "Preparative and analytical purification of DNA from agarose," Proc Natl Acad Sci U S A, vol. 76, No. 2, 1979, pp. 615-619

[5] Karganov M., Alchinova I., Arkhipova E., Skalny A.V., "Laser Correlation Spectroscopy: Nutritional, Ecological and Toxic Aspects," In: "Biophysics". A.N. Misra ed.- InTech, 2012, -ISBN 978-953-51-0376-9. P.1-16. DOI: $10.5772 / 35254$

[6] Kostiuk SV, Zamulaeva IA, Agapova RK, Ermakov AV, Saenko AS, Orlova NV, Smirnova SG, Veǐko NN, Spitkovskiı̌ DM., "The changing of cell-free DNA properties of peripheral blood and TCR-mutant cell frequency in individuals exposed to ionizing radiation," Radiats Biol Radioecol, vol. 48, No.1, 2008, pp.5-13.
[7] Alchinova I., Arkhipova E., Cherepov A., Karganov M., "Polysystemic monitoring of nuclear plant stuff and risk group revealing," In: Risk assessment and management. Zhang Zhiyong ed., 2012, Academy Publish, USA. ISBN: 978-0-9835850-2-2. pp. 193-199.

[8] Vral A., Thierens H., Baeyens A., De, Ridder L., "Chromosomal aberrations and in vitro radiosensitivity: intraindividual versus inter-individual variability," Toxicol. Lett., vol. 149, 2004, pp. 345-352

[9] Anderson H.C., "The spontaneous frequency of chromosomal aberrations and sister-chromatid exchanges in cultured peripheral lymphocytes of a single blood donor sampled more than 200 times," Mutat. Res., 1993, pp.281-292

[10] Kadhim M.A., Lee R., Moore S.R., Macdonald D.A., Chapman K.L., Patel G., Prise K.M., "Genomic instability after targeted irradiation of human lymphocytes: Evidence for inter-individual differences under bystander conditions," Mutat. Res., vol. 688, No. 1-2, 2010, pp.91-94

[11] Ermakov AV, Konkova MS, Kostyuk SV, Smirnova TD, Malinovskaya EM, Efremova LV, Veiko NN., "An extracellular DNA mediated bystander effect produced from low dose irradiated endothelial cells," Mutat Res, vol. 712(12), 2011, pp.1-10. doi: 10.1016/j.mrfmmm.2011.03.002 